\title{
Methodology for Product Development in R\&D Companies
}

\author{
Rodrigo B. OTTO ${ }^{1 a}$, Carlos H. SZOLLOSI ${ }^{2 a}$, Galileu G. TERADA ${ }^{3 b}$, Rodrigo K. \\ HISAMURA $^{4 \mathrm{c}}$, Guilherme ZAT $^{5 \mathrm{a}}$ and João A. PEREIRA ${ }^{6 \mathrm{~d}}$ \\ a ITAIPU Technological Park, Brazil \\ ${ }^{\mathrm{b}}$ ITAIPU Binacional, Brazil \\ c ITAI - Instituto de Tecnologia Aplicada e Inovação, Brazil \\ ${ }^{\mathrm{d}}$ Copel GT, Brazil
}

\begin{abstract}
Due to the speed in which technological advances take place, companies that operate in this field need to implement and follow rigorous process management in order to guarantee their survival and competitiveness in the market. Faced with this need, the question arises as how the management process is carried out within technology-based companies with emphasis on R \& D, in which, due to the short development cycles and low production volumes, it needs to optimize their processes to meet efficiently the customer needs. Intending to obtain knowledge about this subject, the present work documents the process of management and classification of the projects and the products development stages of the Laboratory of Automation and Simulation of Electrical Systems (LASSE) through the development of a documentary research, based on a bibliographical revision regarding the main concepts that compose the theme. Finally, an analysis of the stage of development of the projects according to the process currently adopted was made, comparing it to the classifications of the Innovation Chain, proposed by ANEEL and the Technology Readiness Level, proposed by NASA. It was concluded that following a plan management and the adoption of rating scales is indispensable for the success of the company in meeting its demands within the established deadlines, ensuring the quality of services and products provided to its customers.
\end{abstract}

Keywords. R\&D, Processes Management, Innovation Cycle, Technology Readiness Level, Product Development.

\section{Introduction}

Competitiveness among technology companies increases every day mainly due to the high speed that technological advances occur. In a competitive world, to ensure their survival in the market, technology-based companies (TBC) focusing on research and development (R\&D) need to implement and follow rigorous processes of project management to develop their products. As greater the efficiency of these processes, better will be the use of the available time and financial resources [1].

\footnotetext{
${ }^{1}$ Corresponding Author, Email: rodrigobueno@pti.org.br.

${ }^{2}$ Corresponding Author, Email: carlos.szollosi@pti.org.br.

${ }^{3}$ Corresponding Author, Email: galileu@itaipu.org.br.

${ }^{4}$ Corresponding Author, Email: rodrigo.kenji@itai.org.br.

${ }^{5}$ Corresponding Author, Email: guilherme.zat@pti.org.br.

${ }^{6}$ Corresponding Author, Email: joao.adalberto@copel.com.
} 
According to Jugend [1], among the activities carried out by the TBCs, product development can be considered the most crucial element to remain in the competitive market, due to low-scale production, the low product maturity and also the fast technological advancement, resulting in shorter development cycles. All these characteristics require these companies a solid system of Product Development Process Management (PDM).

Starting from the principle previously exposed, the question arises related to the processes followed by these companies and their main effect on their success. Thus, the main objective of this article is to document a study about the process of managing and classifying the development stages of projects and products in an industrial R\&D company, and, in addition, compare the company's processes under study with the Innovation Chain classifications, proposed by ANEEL, and Technology Readiness Level, proposed by NASA. This study was carried out in the Laboratory of Automation and Simulation of Electrical Systems (LASSE), whose characteristics fit the standard of the company being studied.

\section{Managing the Product Development Process}

The management of the product development process is composed of several phases that must be followed. The successful completion of each of these phases has become of great importance for the success of the projects. In this topic it will be presented the main concepts involved in this work thus the comprehension is indispensable for the theoretical foundation and understanding of the present work.

\subsection{Research and development $(R \& D)$ and technological innovation}

The evolution of electronics, the popularization of the internet and technological advances have brought new challenges for technology-based companies, the main ones are related to the need in remaining competitive in the market to guarantee their continued existence. In order to meet this goal, it is necessary to be always ahead in the development of products to meet the needs of customers, standing out from the competition mainly in terms of cost and quality [2].

Companies started investing in research and development in order to meet the demands for innovation demanded by the market. In this way, companies invest part of their earnings in the search for knowledge, mainly directed to the production of technological solutions. Research and Development (R\&D) is present in all or most of the activities that integrate the innovation process, from the conception of its idea to its conclusion, supporting the solution of problems and serving as a source of innovative ideas [2].

According to the Brazilian National Electric Energy Agency (ANEEL) [3], in the context of its research and development program, an R\&D is a project that leads or seeks the implementation of new or improved products and/or processes. R\&D can also be defined as a form of know-how acquisition, and development of technologically modern tools and equipment, as well as applied industrial engineering in the production of innovations and improvements [3, 4]. 


\subsection{The Innovation Chain}

Spread worldwide, the Frascati Manual [4] subdivides R\&D activities into three categories of projects, wich are: Basic Research; Applied Research and Experimental Development. However, based on this standard, ANEEL's R\&D Handbook classifies R\&D activities in six categories, forming the Innovation Chain illustrated in Figure 1 [5].

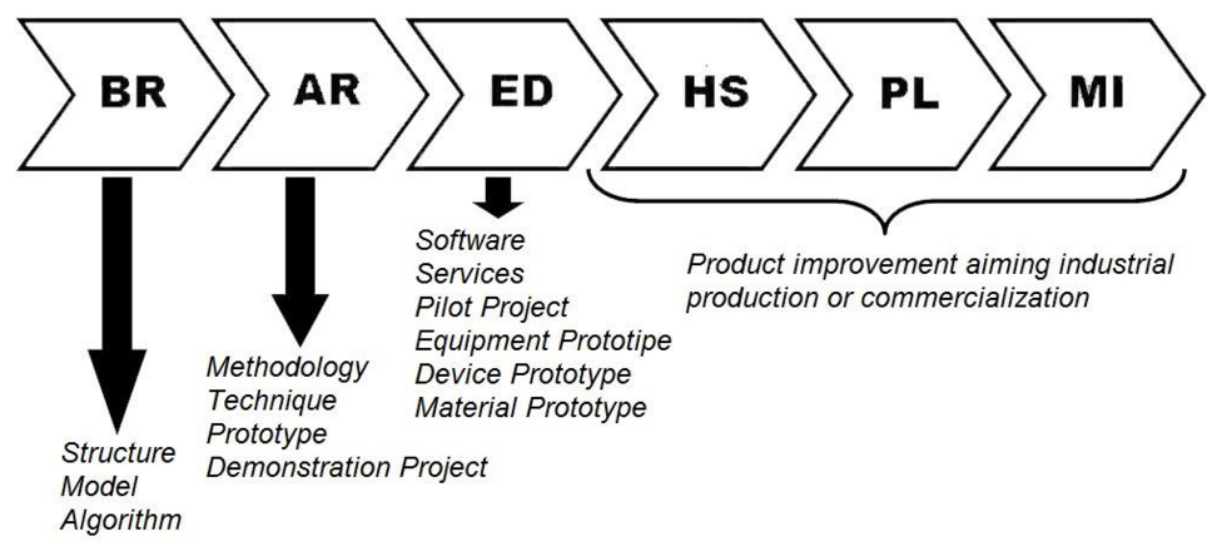

Figure 1. Innovation Chain, adapted from ANEEL, [4, 13].

In this sense, the PROP\&D [5] define the projects of the Innovation Chain as presented in the sequence:

- Basic Research (BR): theoretical or experimental phase destined to the search of knowledge about new phenomena, with a view to the development of innovative products and processes. It involves the analysis of properties, structures and connections to formulate or prove hypotheses, theoris and laws;

- Applied Research (AR): aimed at the application of acquired knowledge, aiming at the development or improvement of products and processes. It leads to the discovery of knowledge applications. Involves the available knowledge and its application in the search of oppurtunities or solutions of problems and challenges;

- Experimental Development (ED): systematic phase, outlined from pre-existing knowledge. It is, therefore, the process of transformation or refinement of knowledge coming from Basic Research or Applied Research in operational programs, including demonstration projects and tests.

These first three types of projects require high degree of originality and technological innovation. The degree of maturation necessary for the improvement of the newly developed solutions for industrial production and its commercialization is achieved through projects within the following phases of the Innovation Chain. For these the PROP\&D define:

- Head Series (HS): improvement phase of prototype obtained in previous R\&D project, seeking to improve design and specifications of the prototype for scale reproduction and taking into account aspects related to the definition of the production line and the product;

- Pionner Lot (PL): aspects related to the scale production of a series head developed in a previous $\mathrm{R} \& \mathrm{D}$ project are considered, where a small scale 
production is carried out with a view to validation, cost analysis and refining of the project for future industrial production and/or commercialization;

- Market Insertion (MI): it closes the chain of innovation, seeking to disseminate the results obtained in the electric sector. These projects include market research activities, dissemination material, patent registration and legal services.

According to the Frescati Manual [4], these last three types of projects are not considered typical of $R \& D$, but extremely important for the continuity of the innovation process, because it is through them that it is possible to disseminate new technologies in the form of new products $[6,7]$.

\subsection{Technology Readiness Level}

Another way to classify development levels, which are found in innovation projects, was developed in its first version in 1974 by the National Aeronautics and Space Administration (NASA) researcher, Stan Sadin. Named Technology Readiness Level (TRL), it was initially divided into seven levels by 1989. Currently the TRL scale has nine levels and has been applied by NASA since the 1990s in the classification of its projects [8].

Based on the documents describing the TRL application by NASA, the European Space Agency and the Department of Defense of the United States, the TRL scale was standardized by ISO 16290: 2013 [9].

The nine levels of the TRL scale can be defined as [10]:

- $\quad$ TRL-1 - Basic principles observed and reported: corresponds to the lower level of technological maturation, being composed by basic research of scientific nature focusing on applied research and development;

- TRL-2 - Technology concept and/or application formulated: The results obtained in the previous level are applied on practical solutions. At this level, the application of the technology is still in the speculative stage of study, without experimental evidence to prove the concept;

- TRL-3 - Analytical and experimental critical function and/or characteristic proof-of-concept: Comprises both analytical and experimental approaches to the concepts studied at level TRL-2. This phase is characterized by the beginning of the applied research phase, where the concepts studied are tested and validated;

- TRL-4 - Component and/or breadboard validation in laboratory environment: validation in the laboratory through the use of simulators and the integration of individually tested components at the previous level in order to verify if they will be able to work together and thus make up the complete system, but without great fidelity to the system as a whole;

- TRL-5 - Component and/or breadboard validation in revelant environment: at this level the simulated test occurs in an environment very close to the real one, through the integration of the components in development. The tests are carried out in configuration with close proximity to the total application;

- TRL-6 - System/sub-system model or prototype demonstration in a relevant environment: at this stage the prototype, subsystem or component, in scale, goes through the performance tests in the real operating environment. It 
corresponds to an important step in development because it provides results regarding to behavior of the prototype or system under hostile operating conditions when integrated with other systems;

- TRL-7 - System prototype demonstration in the expect operational environment: demonstration in real environment of the prototype system operation. The prototype should be close to or in the real scale of the application for which it is intended;

- TRL-8 - Actual system completed and "qualified" throught test and demonstration: represents the last stage of real system development. At this stage, the complete system undergoes demonstration tests in its operating environment. This level also involves technologies that will be integrated with systems already in operation;

- TRL-9 - Real system approved in the full range of expected conditions: operation of the approved technology in its operating environment.

\section{Metodology}

The present work consists of a case study, which can be defined as a way to obtain knowledge about an item that represents a specific class, be it an individual, group or institution, in order to acquire expertise on its operation and/or behavior [11]. In this case study, a documentary research was carried out in order to obtain information about the process of managing the development of products in an industrial R\&D company.

In order to obtain the basic knowledge needed to understand the most important topics related to the subject, a bibliographical research was carried out, which consisted in obtaining the state of the art on the subject through consultations with published theoretical references [11].

The relevant data of the company under study were obtained from documentary research that was performed based on technical files and presentation of the activities developed by the institution. The information obtained in this research was organized and presented in the following sections.

At the end of the work, a comparative study was performed to verify the degree of adherence of the company's processes under study with classification models found in the literature, proposed by ANEEL (Innovation Chain) and NASA (Technology Readiness Level). Through this study it will be possible to verify the distribution of all existing projects in each of the types of classification, allowing to analyze in detail the different scenarios improving the current methodology.

\subsection{The Company}

The LASSE - Laboratory of Automation and Simulation of Electrical Systems is an institution located in the Technological Park of the ITAIPU Hydroelectric Power Plant (PTI) whose mission is to develop $\mathrm{R} \& \mathrm{D}$ projects focused on supporting the Technological Update of ITAIPU and also on the realization of electrical studies by means of simulations of the electric power system [12].

The current structure of LASSE is basically composed of two development sectors:

- Electrical Studies Laboratory: responsible for carrying out studies aimed at the operation of the electric power system through mathematical modeling and 
simulation of its main elements using computers with high processing capacity [12].

- Automation Laboratory: responsible for the development of monitoring systems, using state-of-the-art technologies available in the market; development of embedded systems, composed of electronic devices and customized software dedicated to hardware devices (both market and own development); realization of assembly of industrial panels, following the most demanding norms of the industry, contemplating from its design to the technical documentation required by the sector; conducting research and development through R\&D projects in order to obtain solutions for the Brazilian electricity sector [12].

\subsection{LASSE Production Management}

In order to execute the Service Orders (S.O.) from customers demands, LASSE has a project management and development process which uses a structured management system to guide the activities carried out by the entire team [13].

The management process developed by LASSE is divided into ten predefined steps that are grouped into four main phases, as shown in Figure 2. The accomplishment of these phases has been indispensable for the company's success in meeting the demands within the established deadlines and the quality of services and products made [14].

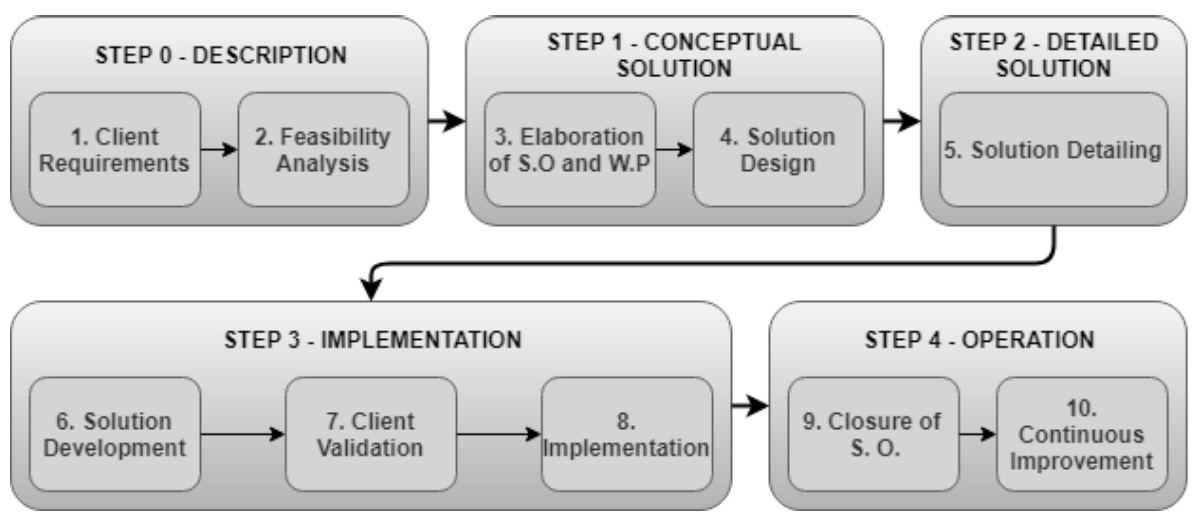

Figure 2. LASSE Process Flowchart, adapted from [14].

The following topics provide a detailed description of each of these phases and their respective activities.

\subsubsection{Description (STEP 0)}

In this phase occurs the first contact between the client and the company in which the activities of the demand start. From presentation of the demand, the team performs the collections of the Client Requirements to execute the project, resulting in the macro requirements and also in the preliminar schedule of the project [14].

From the results obtained in the collection of customer requirements, a feasibility analysis of project execution is done. At this stage it is evaluated whether the existing competencies and the LASSE infrastructure meet the requirements necessary for the 
execution of the project. The results of this step are presented to the functional manager so that decisions are made regarding the continuity of the project, resulting in a document called technical report $[13,14]$.

\subsubsection{Conceptual Solution (STEP 1)}

With the technical approval for continuity of the project and performing new meetings with the client, additional and more detailed requirements are collected that will be used for the elaboration of the Order of Service (O.S) and Work Plan (W.P) of the project [14].

During the preparation of the O.S, the team performs an estimation of the main deliverables of the project, a schedule and the resources that will be demanded by each area of the company. In the Work Plan, all the information and items that are crucial to the beginning and execution of the project are described, such as: the project coordinator, execution schedule and verification of the steps, evaluation criteria of the deliverables, responsibilities, communication matrix, training and consultancies, among others [14].

Aiming the approval of O.S. and W.P., the development of the "Solution Design" is started, when new meetings are held with the client in order to collect detailed information about his needs, resulting in the most important document for detailing the solution, the Workstatement. Depending on the developed project, usually at this stage, R\&D activities are initiated to obtain the first proofs of concept that will result in the first prototypes of the solution $[13,14]$.

\subsubsection{Detailed Solution (STEP 2)}

"Solution Detailing" is done through the preparation of technical documents necessary for the development of the project by the technical team. Part of these documents are diagrams of orientation for development of software, drawings, documents of architectures for development of hardware, among others. The results of this stage will be used as a guide for the team in the development phase, being therefore of great importance for the continuity and the quality of the project $[13,14]$.

\subsubsection{Implementation (STEP 3)}

After establishing deadlines and schedules, the "Solution Development" begins. In this step the technical team dedicates its activities to implement software and / or hardware that will compose the solution. During the development, internal tests are done to ensure the quality of the product, and the entire development process is monitored by the client through meetings, validating each of these stages according to the progress of the project [14].

Once the functional prototype design is finished, tests are executed according to the client's requirements, according to the Test Plans or Test Procedures. In the implementation phase, the product is assembled and installed in the field and then goes through the commissioning tests, acceptance tests and for an experimental period of operation $[13,14]$

\subsubsection{Operation (STEP 4)}

In this step, the pilot batch is delivered as well as the final project management procedures, where the closing terms are prepared and signed by the client and other parties. These documents allow the closing of the O.S. The final report is also presented 
describing all the activities carried out during the the project. Finally, the plans of Continuous Product Improvement are presented. [13, 14].

\subsection{Classification and adherence of the projects developed by LASSE to the models of} the Innovation Chain (ANEEL) and Technology Readiness Level (NASA)

Currently LASSE has a total of thirty-seven projects being developed, or even concluded. The recent increase in the number of projects has led to an increase in management complexity, turning the knowledge about the particularities of the phases of project indispensable for the great progress of the activities, therefore meeting the deadlines and improving management of financial and human resources.

Through the performed studies, it was realized that the current classification adopted by LASSE described in the previous subsection, as well as the scale proposed by ANEEL, are too generalist during the early stages of development, for the some of the analyzed projects.

Therefore a study was carried out aiming to reclassify each project, within the TRL classification, and by analyzing the results, it was possible to investigate which model could fit to improve the company classification and management processes.

Thus, first of all, through the theoretical definitions of each classification level, a comparison was made between the LASSE and the ANEEL/TRL scales, as presented in Table 1.

Table 1. Comparative analysis between classification levels: Inovation Chain, TRL and the process applied to LASSE

\begin{tabular}{|c|c|c|}
\hline PROCESSO LASSE & CI (ANEEL) & TRL (NASA) \\
\hline STEP 0 - DESCRIPTION & \multirow[b]{2}{*}{ BASIC RESEARCH } & $\mathrm{TRL}-1$ \\
\hline $\begin{array}{l}\text { STEP } 1 \text { - CONCEPTUAL } \\
\text { SOLUTION }\end{array}$ & & $\mathrm{TRL}-2$ \\
\hline \multirow{4}{*}{$\begin{array}{l}\text { STEP } 2 \text { - DETAILED } \\
\text { SOLUTION }\end{array}$} & \multirow{2}{*}{ APPLIED RESEARCH } & $\mathrm{TRL}-3$ \\
\hline & & TRL -4 \\
\hline & \multirow{2}{*}{$\begin{array}{l}\text { EXPERIMENTAL } \\
\text { DEVELOPMENT }\end{array}$} & $\mathrm{TRL}-5$ \\
\hline & & TRL -6 \\
\hline \multirow{2}{*}{$\begin{array}{c}\text { STEP } 3 \text { - } \\
\text { IMPLEMENTATION }\end{array}$} & \multirow{2}{*}{ FUNCTIONAL PROTOTYPE } & $\mathrm{TRL}-7$ \\
\hline & & $\mathrm{TRL}-8$ \\
\hline \multirow{2}{*}{ STEP 4 - OPERATION } & FIRST RUN PRODUCTION & \multirow{2}{*}{$\mathrm{TRL}-9$} \\
\hline & MARKET INSERTION & \\
\hline
\end{tabular}

Then, the projects were properly classified within the levels for both scales. The graphs presented in Figure 3 represent respectively the number of projects classified in the scales proposed by ANEEL and NASA. 

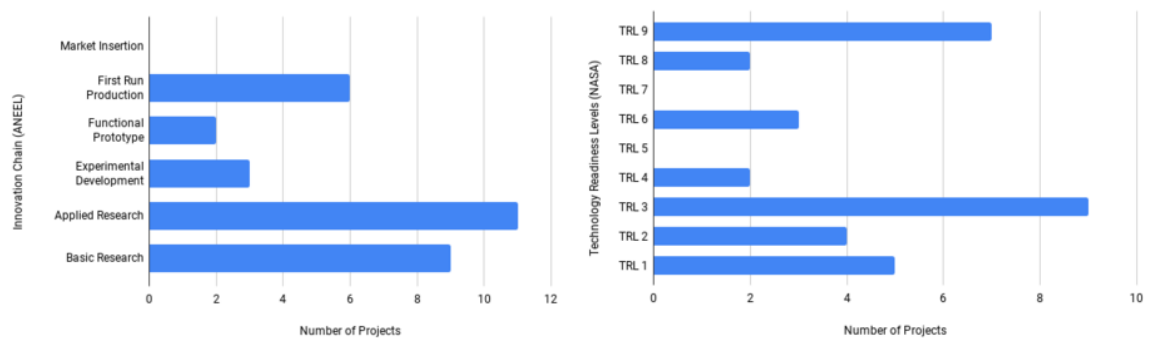

Figure 3. Classification of LASSE Projects.

Analyzing the graphs it is possible to verify that most of the projects are in the first levels of both scales, however, the TRL scale presents a better detail of this distribution.

\section{Considerations and Conclusions}

Analyzing the proposed development scales it is possible to conclude that adopting a more detailed classification methodology offers a better control of the stages in each one of the projects, bringing along improvements in the management of available resources. In the same way, within each development, the expertise obtained results in maturation of the company that moves to a new level where the trust placed by the client and the success of the projects carried out guarantee their growth and place in the competitive market.

Based on the study performed during the documentary research on LASSE, it was observed that the steps followed in the development of its projects correspond directly to the phases of the Innovation Chain proposed by ANEEL, mainly in the startup phase of the functional prototype and in the first run production, where the company assumes industrial characteristics and begins to produce, even in a small scale, the result of its R\&D process. However, in the early stages of development, such classification model is too generic for some projects and a better detailed stages could be of great value..Considering this, the TRL classification model proposed by NASA could possible attend better all levels of development, being the best choice between the presented models for classifing the projects.

Among several reasons that involve the application of the TRL scale in replacement or complemention to the scale proposed by ANEEL, it is due to the better detailing of each level that it is possible a better classification of the projects through the development stages. Another reason for the use of the TRL scale is the possibility of having better control in the management of each project, making possible to optimize the distribution of available human and financial resources, as well as to facilitate the decision-making process.

Essentials characteristics for the success of the projects developed in the company are: the commitment of the team to the deadlines, the high quality of the rendered services, the possibility of customizing the product according to the needs of the client, the support offered to the clients by technical assistance, maintenance and upgrades offered by the team, as well as the technical documentation provided by the company in the delivery of the product, these characteristics are fundamental as they also add intangible values to the product and make it stand out in the market.

Not addressed in this article, however, as a topic of future work, the process is still at the level of R\&D project execution activities, since LASSE has develop the MoP\&D 
(Product Development Model Oriented for R\&D Projects of The Brazilian Electricity Sector) by researchers from COPEL (Energy Company of Parana in Brazil) with a view to their R\&D projects. Based on well-estabilished models of the product development process in line with ANEEL criteria [6], MoP\&D may well be applied to NASA Technology Readiness Levels fundamentals, since it has alson been strutured based on global models of the process development of innovative products [15].

The accomplishment of the present work was of great importance in obtaining knowledge on processes of production management and classification of the stages of development through the practice, from the conception of the project until the delivery of the final product.

\section{References}

[1] D. Jugend, Desenvolvimento de produtos em pequenas empresas de base tecnológica: Práticas de gestão no setor de Automação e Controle de Processos. 2006. 167 f. Dissertação (Mestrado) - Curso de Pósgraduação em Engenharia de Produção, Universidade Federal de São Carlos, São Carlos, 2006.

[2] OCDE, Organização de Cooperação e Desenvolvimento Econômico. Manual de Frascati, 2002: Metodologia proposta para definição da pesquisa e desenvolvimento experimental. Tradução: FINICIATIVAS P+D+I. Tradutor: Oliver Isnard, 2013.

[3] OCDE, Organização de Cooperação e Desenvolvimento Econômico. Manual de Oslo, 1997: Diretrizes para coleta e interpretação de dados sobre a inovação. 3 ed. Produção: ARTI/FINEP. Tradutor: Flávia Golveia, 1997.

[4] Frascati Manual: Proposed standard practices for surveys on research and experimental development. 6. ed. OECD (Organization for Economic Co-Operation and Development), Paris, France, 2002.

[5] ANEEL, Agência Nacional de Energia Elétrica. Procedimentos do Programa de Pesquisa e Desenvolvimento - PROP\&D - Módulo 2, 2017. Disponível em: http://www.aneel.gov.br/. Acessed Jan12, 2017.

[6] J.A. Pereira and O. Canciglieri Junior, Modelo de desenvolvimento integrado de produto orientado aos projetos de $P \& D$ do setor elétrico brasileiro - MoP\&D, 1 ed., Novas Edições Acadêmicas, Alemanha, 2016.

[7] A.F. Cabello and F.M. Pompermayer, Impactos Qualitativos do programa de P\&D regulado pela ANEEL. In: Inovação tecnológica no setor elétrico brasileiro: uma avaliação do programa de P\&D regulado pela ANEEL. 1. ed. IPEA, Brasília, DF, Brazil, 2011.

[8] NASA, Technology Readiness Levels Demystified. 2010. Disponível em: $<$ https://www.nasa.gov/topics/aeronautics/features/trl_demystified.html >. Acessed Mar 01, 2019.

[9] E.A.D. Moresi, at. al. Análise de níveis de prontidão: uma proposta para empresas nascentes. ISQR2017 International Symposium on Qualitative Research. Espanha, 2017. https://proceedings.ciaiq.org/index.php/ciaiq2017/article/view/1127

[10] J.C. Mankins, Technology readiness assessments: A retrospective. Artemis Innovation Management Solutions LLC, Ashburn, VA, USA. 2009.

[11] A.L. Cervo et al. Metodologia Cientifica. 6. ed. Pearson Prentice Hall, São Paulo, 2007.

[12] LASSE, Laboratório de Automação e Simulação de Sistemas Elétricos. Apresentação: Novo LASSE. 03/01/2017a (Arquivos Internos)

[13] C. H. Szollosi, et al. Estudo sobre o desenvolvimento de produtos em ambiente de P\&D, SINGEP18.

[14] LASSE, Laboratório de Automação e Simulação de Sistemas Elétricos. Gestão do Conhecimento LASSE: Fluxo de Execução de Ordem de Serviço. 06/02/2017b (Arquivos Internos).

[15] J.A. Pereira, M. Penha, O. Canciglieri Jr, R.B. Otto and V.R. Mognon, New Application of Product Development Model Oriented to the R\&D Program of Brazilian Electrical Sector for Planning a Product Project, Advances in Transdisciplinary Engineering, Vol. 7: Transdisciplinary Engineering Methods for Social Innovation of Industry 4.0, IOS Press, Amsterdam, 2018, pp. 431-440. 